\title{
Foveal relocation by redistribution of the neurosensory retina
}

\author{
David Wong, Noemi Lois
}

\begin{abstract}
Aim-To describe a new surgical technique for foveal relocation, and to report the outcome in nine patients treated with this procedure.

Methods-Nine consecutive patients with subfoveal choroidal neovascular membranes (CNVMs) secondary to age related macular degeneration underwent foveal relocation surgery by redistribution of the neurosensory retina (RNR). The technique involved induction of a retinal detachment via a single retinotomy, relocation of the fovea by "sweeping" the retinal tissue with a retinal brush, and stabilisation of the retina in its new location using perfluorocarbon liquid peroperatively and silicone oil postoperatively.
\end{abstract}

Results-In eight of nine eyes successful relocation of the fovea was achieved; in one eye the CNVM remained in a subfoveal location postoperatively. Visual acuity improved in two eyes, remained unchanged in three, and decreased in four eyes after a median follow up of 4 months (range 2.5-6 months). Complications included rupture of a foveal cyst with the development of a macular hole in one eye and epimacular membrane formation in another eye. In two eyes, macular retinal vessel closure occurred at the time of laser photocoagulation; one of these eyes later developed cystoid macular oedema and the other an epiretinal membrane. Recurrence of the CNVM was observed in one eye, but was controlled with further laser treatment.

Conclusions-Foveal relocation by RNR appears to be feasible, obviating the need for extensive retinotomies or scleral shortening.

(Br f Ophthalmol 2000;84:352-357)

Randomised controlled clinical trials have demonstrated the value of laser photocoagulation for the treatment of well defined extrafoveal, juxtafoveal, and subfoveal choroidal neovascular membranes (CNVMs). ${ }^{1-5}$ However, only a small proportion of patients with age related macular degeneration (ARMD) and CNVM meet the Macular Photocoagulation Study (MPS) criteria for laser treatment. Furthermore, although long term benefit from laser photocoagulation has been shown in cases of subfoveal CNVM, permanent visual loss invariably occurs following this procedure. ${ }^{3-5}$ The limitations of laser photocoagulation for the treatment of subfoveal CNVM in the con- text of ARMD have prompted investigators to search for alternative forms of treatment. Thus, radiation ${ }^{6-8}$ and photodynamic therapy $^{9-11}$ are under study. The initial enthusiasm for the surgical excision of subfoveal CNVM in ARMD has been dampened by the disappointing visual results often obtained using this technique. ${ }^{12-15}$ This form of therapy is also being evaluated in a prospective randomised multicentre clinical trial.

In 1993 Machemer and Steinhorst ${ }^{16}{ }^{17}$ proposed a new surgical approach to the management of subfoveal CNVM. By creating a total retinal detachment (RD) and using a 360 degree peripheral retinotomy, they were able to move the fovea to an area of healthy retinal pigment epithelium (RPE) and choroid, away from the CNVM. Although the idea appeared to be very promising, complications associated with the surgical procedure were common. Two of the three patients reported developed retinal detachment and proliferative vitreoretinopathy (PVR) impairing the final visual outcome. Since this initial description, several attempts have been made to try to reduce the difficulty of, and complications arising from, the surgical procedure. ${ }^{18-23}$ Ninomiya and associates ${ }^{18}$ proposed the use of a 180 degree retinotomy in order to limit the area of exposed $\mathrm{RPE}$ and thus to reduce the risk of subsequent PVR. Scleral shortening techniques by scleral resection ${ }^{20}$ or imbrication ${ }^{23}$ have also been used to obtain the retinal redundancy required to translocate the fovea and to avoid the need for large retinotomies.

Spectacular improvements in visual acuity, as observed in several patients after macular relocation surgery ${ }^{20-22}$ but never achieved using other forms of therapy, have encouraged vitreoretinal surgeons to develop safer and more predictable surgical techniques. In this report, we present a novel surgical procedure for foveal relocation. The technique is based on the principle that redundancy of retinal tissue, required to displace the fovea, can be obtained by redistribution of the neurosensory retina with no need for scleral shortening or relieving retinal incisions. Results obtained in nine consecutive patients with subfoveal CNVMs managed by this technique are presented.

\section{Patients and methods}

Nine consecutive patients with subfoveal CNVMs secondary to ARMD underwent foveal relocation surgery by the technique of redistribution of the neurosensory retina (RNR). All patients met the following inclusion criteria: (1) subfoveal classic CNVM, with or without an occult component, (2) symp-
Accepted for publication 22 December 1999 
Table 1 Demographics, preoperative characteristics, visual outcome, and follow up in nine patients with subfoveal choroidal neovascular membranes undergoing foveal relocation surgery

\begin{tabular}{|c|c|c|c|c|c|c|c|c|c|c|c|}
\hline \multirow[b]{3}{*}{ Patient } & \multirow[b]{3}{*}{ Age } & \multirow[b]{3}{*}{ Sex } & \multirow[b]{3}{*}{ Affected eye } & \multirow{3}{*}{$\begin{array}{l}\text { Duration } \\
\text { symptoms }\end{array}$} & \multirow{3}{*}{$\begin{array}{l}\text { Follow up } \\
\text { (months) }\end{array}$} & \multicolumn{4}{|c|}{ Visual acuity* } & \multirow[b]{3}{*}{ Choroidal type } & \multirow{3}{*}{$\begin{array}{l}\text { Neovascular } \\
\text { membrane size } \\
\text { (MPS disc } \\
\text { areas)t }\end{array}$} \\
\hline & & & & & & \multicolumn{2}{|c|}{ Preoperative } & \multicolumn{2}{|c|}{ Postoperative } & & \\
\hline & & & & & & Distance & Near & Distance & Near & & \\
\hline 1 & 70 & $\mathrm{~F}$ & LE & 4 & 5 & $6 / 60$ & N36 & $6 / 24$ & N12 & Classic & 1 \\
\hline 2 & 54 & $\mathrm{~F}$ & $\mathrm{RE}$ & 6 & 6 & $6 / 18$ & N24 & $6 / 60$ & N24 & Classic & 1 \\
\hline 3 & 79 & $\mathrm{~F}$ & $\mathrm{RE}$ & 8 & 4 & $6 / 36$ & NA & $6 / 36$ & N18 & Classic & 9 \\
\hline 4 & 69 & $\mathrm{~F}$ & LE & 2,5 & 4 & $6 / 24$ & NA & $6 / 12$ & N6 & Classic and occult & 2 \\
\hline 5 & 73 & $\mathrm{~F}$ & LE & 1,5 & 2,5 & $6 / 36$ & N18 & $6 / 36$ & NA & Classic & 3 \\
\hline 6 & 71 & $\mathrm{~F}$ & $\mathrm{RE}$ & 4 & 4,5 & $2 / 60$ & N36 & $2 / 60$ & N36 & Classic & 3 \\
\hline 7 & 81 & $M$ & $\mathrm{RE}$ & 1 & 4 & $6 / 18$ & N24 & $2 / 60$ & NA & Classic & 2 \\
\hline 8 & 70 & $\mathrm{~F}$ & LE & 3 & 3 & $6 / 18$ & $\mathrm{~N} 24$ & $1 / 60$ & NA & Classic & 1 \\
\hline 9 & 77 & $M$ & $\mathrm{RE}$ & 5 & 4 & $6 / 18$ & N14 & $3 / 60$ & N36 & Classic & 2 \\
\hline
\end{tabular}

^Best corrected visual acuity, $\nmid$ size of the classic component, $\mathrm{NA}=$ not available.

Table 2 Complications in nine patients with subfoveal choroidal neovascular membranes undergoing foveal relocation surgery

\begin{tabular}{ll}
\hline Patient & Complications \\
\hline 1 & None \\
2 & Vessel occlusion, CMO \\
3 & RPE changes \\
4 & None \\
5 & RPE changes \\
6 & Macular hole \\
7 & Insufficient translocation \\
8 & ERM \\
9 & Vessel occlusion, ERM, recurrence of CNVM
\end{tabular}

$\mathrm{CNVM}=$ choroidal neovascular membrane, $\mathrm{CMO}=$ cystoid macular oedema, ERM = epiretinal membrane, $\mathrm{RPE}=$ retinal pigment epithelium.

toms of decreased visual acuity present for less than 8 months, (3) visual acuity of $6 / 18$ or worse, (4) signs of ARMD, such as drusen, in the affected and/or in the fellow eye, and (5) absence of marked and diffuse RPE changes in the macula.

There were seven females and two males with a median age of 71 years (range 54-81 years). The median duration of symptoms was 4 months (range 1-8 months). Preoperative characteristics of the patients are summarised in Tables 1 and 2. Preoperative best corrected visual acuity in the operated eye ranged from $6 / 18$ to $2 / 60$. Visual acuity in the fellow eye was better than in the operated eye in four patients, whereas in five patients the fellow eye had the worse visual acuity. In eight eyes fluorescein angiography disclosed a classic CNVM, whereas in one eye (patient 4) an occult component was also present. The median size of the classic component of the CNVM was 2 MPS disc areas (range 1-9 MPS disc areas). No patient had previously undergone laser treatment to the CNVM.

Best corrected visual acuity, measured with Snellen visual acuity charts, intraocular pressure (IOP), anterior segment findings on slit lamp examination and posterior segment findings on slit lamp biomicroscopy, and indirect ophthalmoscopy were assessed preoperatively and postoperatively. In addition, colour fundus photography and fluorescein angiography were performed preoperatively and during the course of follow up. The follow up period was considered as the time between the foveal relocation surgery and the last follow up visit. Patients were followed for 2.5-6 months (median 4 months).
Foveal relocation surgery was considered to be successful when the CNVM was no longer in a subfoveal location, based on slit lamp biomicroscopy and fluorescein angiography.

SURGICAL TECHNIQUE FOR RNR

A three port pars plana vitrectomy was performed, including detachment and excision of the posterior hyaloid when necessary. The

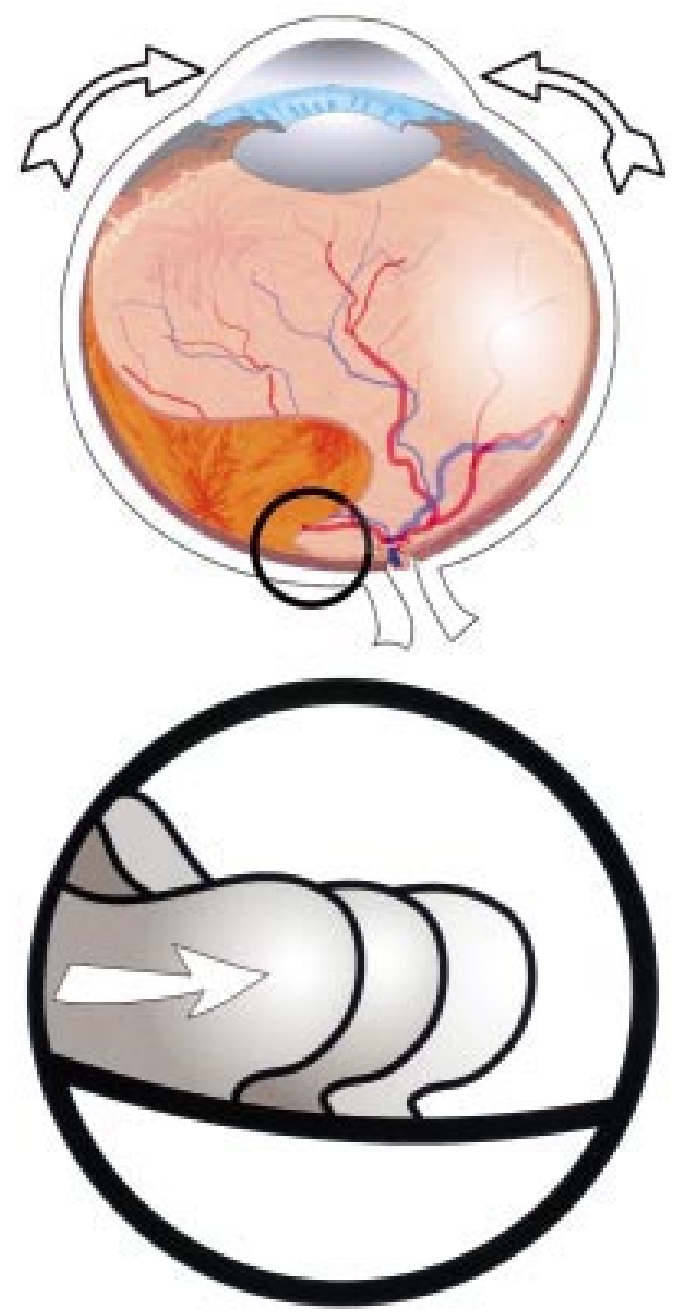

Figure 1 Scheme representing the manoeuvre used to achieve a total retinal detachment. Once detachment of one quarter to one third of the retina was obtained by infusion of saline into the subretinal space, the air filled eye was subjected to a gentle rocking motion (arrows) (top). The inertia created by the weight of the subretinal fluid (bottom) was used to extend the detachment "tidally". 


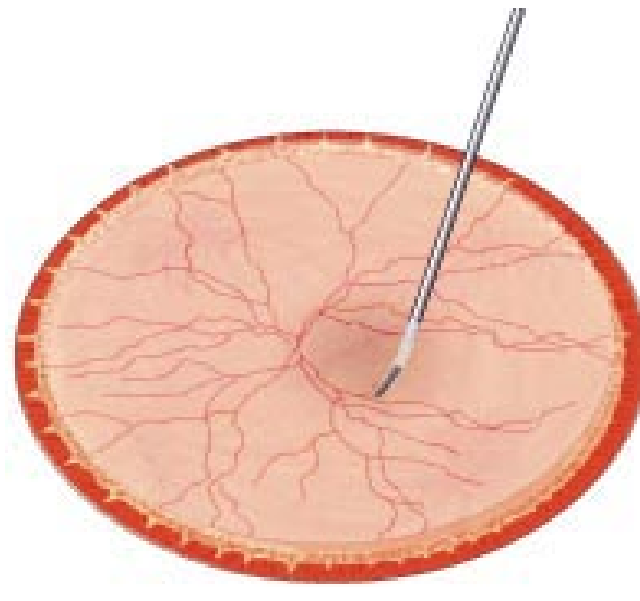

Figure 2 Using a retinal brush the shallowly detached fovea was relocated by gently "sweeping" the retinal tissue.

vitreous base was then tightly trimmed using a bimanual technique of deep indentation. A localised retinal detachment was induced using a 32 gauge infusion cannula (Lambert subretinal injector, Visitec, Sarasota, FL, USA) via a single retinotomy located in the postequatorial retina anterior to the superotemporal major vascular arcade. Saline solution was used for the subretinal infusion, which was continued until one quarter to one third of the retina was detached. At this point, a fluid-air exchange was performed, resulting in posterior sequestration of subretinal fluid. All preretinal fluid was evacuated, and the eye was subjected to a gentle rocking motion (Fig 1 (top)). The weight of the subretinal fluid in the air filled eye produced an inertia when the eye was agitated (Fig 1 (bottom)) which was used to extend the detachment "tidally" into the macula and to achieve a total retinal detachment. Most of the subretinal fluid was then evacuated by internal drainage, which was achieved, in most cases, using the same retinotomy site. With the vitreous cavity filled with fluid and the macula only shallowly detached, the fovea was relocated by gently "sweeping" the retinal tissue with a retinal brush (Grizzard vitreoretinal brush, Visitec, Sarasota, FL, USA) (Fig 2). The decision to move the retina either upwards or downwards was made based on the appearance of the RPE on preoperative slit lamp biomicroscopy, fluorescein angiography, and on the distance from the centre of the fovea to the margin of the CNVM. Thus, when possible, the fovea was moved to an area with "healthy looking" RPE using the least amount of retinal movement that would allow clearance of the fovea from the CNVM. When the fovea appeared to be sufficiently far from the CNVM to permit postoperative laser photocoagulation of the CNVM without damaging the fovea, perfluorocarbon liquid (PFCL) (F-octane, Fluoron GMBH, Neu-Ulm, Germany) was injected in order to maintain the retina in its new location. The surgery was completed with a direct silicone oil/PFCL exchange. Postoperatively, the CNVM was treated with argon green laser and, later, the silicone oil was removed. The latter procedure was combined with phacoemulsification and intraocular lens implantation in all nine patients. Phacoemulsification and silicone oil removal were performed at a median time of 7 weeks (range 4-12 weeks). The median time between phacoemulsification and silicone oil removal and the last follow up visit was 7 weeks (range 1-20 weeks).

\section{Results}

The fovea was successfully relocated intraoperatively in eight of nine eyes. In one eye (patient 7) slippage occurred during PFCLsilicone exchange. Rupture of a central foveal cyst in one eye (patient 6) with pre-existing cystoid macular oedema (CMO) resulted in a full thickness macular hole.

Postoperatively, the CNVM was juxtafoveal or extrafoveal in eight eyes (Figs 3-5), and remained subfoveal in one (patient 7 ). In all but one eye (patient 7) photocoagulation could be applied to the CNVM after foveal relocation surgery. In two eyes (patients 2 and 9), closure of a macular retinal vessel occurred at the time of laser photocoagulation. In one eye (patient 9) recurrence of the CNVM was detected 2 months after laser treatment, and required and was controlled with further photocoagulation (Table 1). In one eye (patient 4 ) an area of persistence of CNVM in the non-foveal side was appreciated; this area remained stable during the follow up requiring no further treatment.
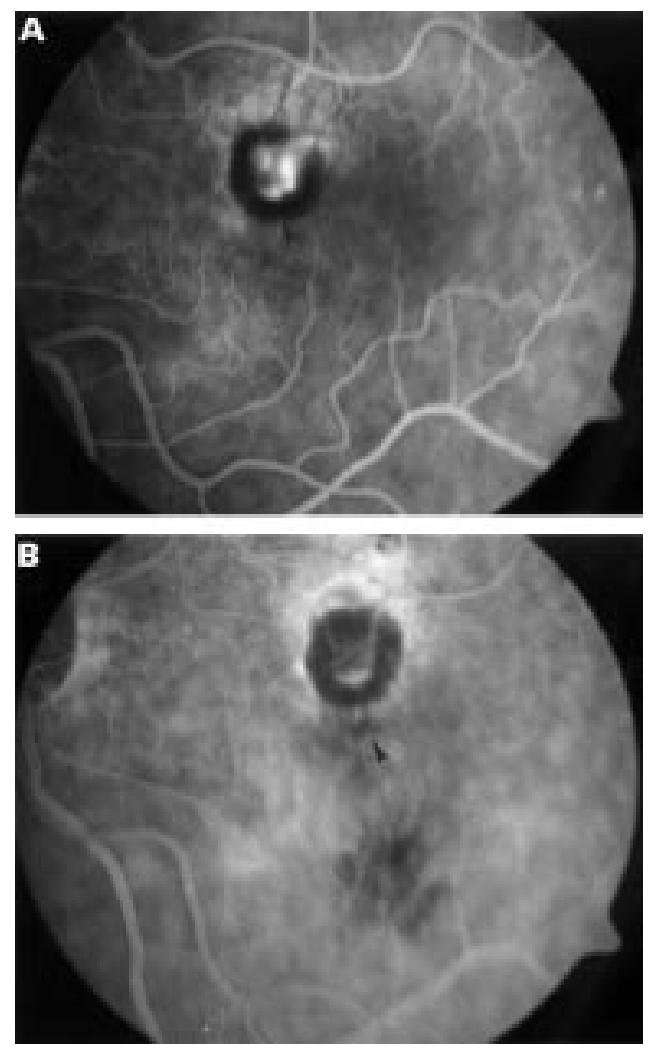

Figure 3 (A) Preoperative fluorescein angiogram of the left eye of patient 1, showing dye leakage from a classic subfoveal CNVM. A halo of hypofluorescence corresponded to a ring of hyperpigmentation on fundus examination. The centre of the fovea was located within the pigmented ring (arrowhead). (B) Postoperatively, the CNVM was extrafoveal (arrowhead indicates site of fovea after relocation). 
Slit lamp biomicroscopy and fluorescein angiography disclosed RPE changes, not seen preoperatively, in two patients (patients 3 and $5)$. In the other seven cases no major changes in the RPE were detected when comparing preoperative and postoperative fluorescein angiograms.

At the last follow up visit, visual acuity had improved in two eyes, remained the same in three eyes, and worsened in four eyes. Other complications observed during follow up included epiretinal membrane (ERM) formation at the macula in two eyes (patients 8 and 9), and $\mathrm{CMO}$ in one (patient 2).

\section{Discussion}

Although macular relocation surgery appears to be a promising method of treatment for subfoveal CNVM, the procedure can be associated with a number of complications. One of the most devastating complications is the occurrence of proliferative vitreoretinopathy (PVR). ${ }^{17}{ }^{18}$ PVR has been observed frequently $(33 \%-43 \%)$ after 360 degree and 180 degree retinotomies, ${ }^{17} 1824$ and appears to be related to the extent of exposure of the RPE. However, in a recent study by Eckardt and associates ${ }^{25}$ (in which macular rotation was achieved in 30 patients by using a 360 degree retinotomy), retinal detachment occurred in five patients, and PVR in only three. The low rate of PVR in this series could be related to very thorough trimming of the vitreous base, to the perform-
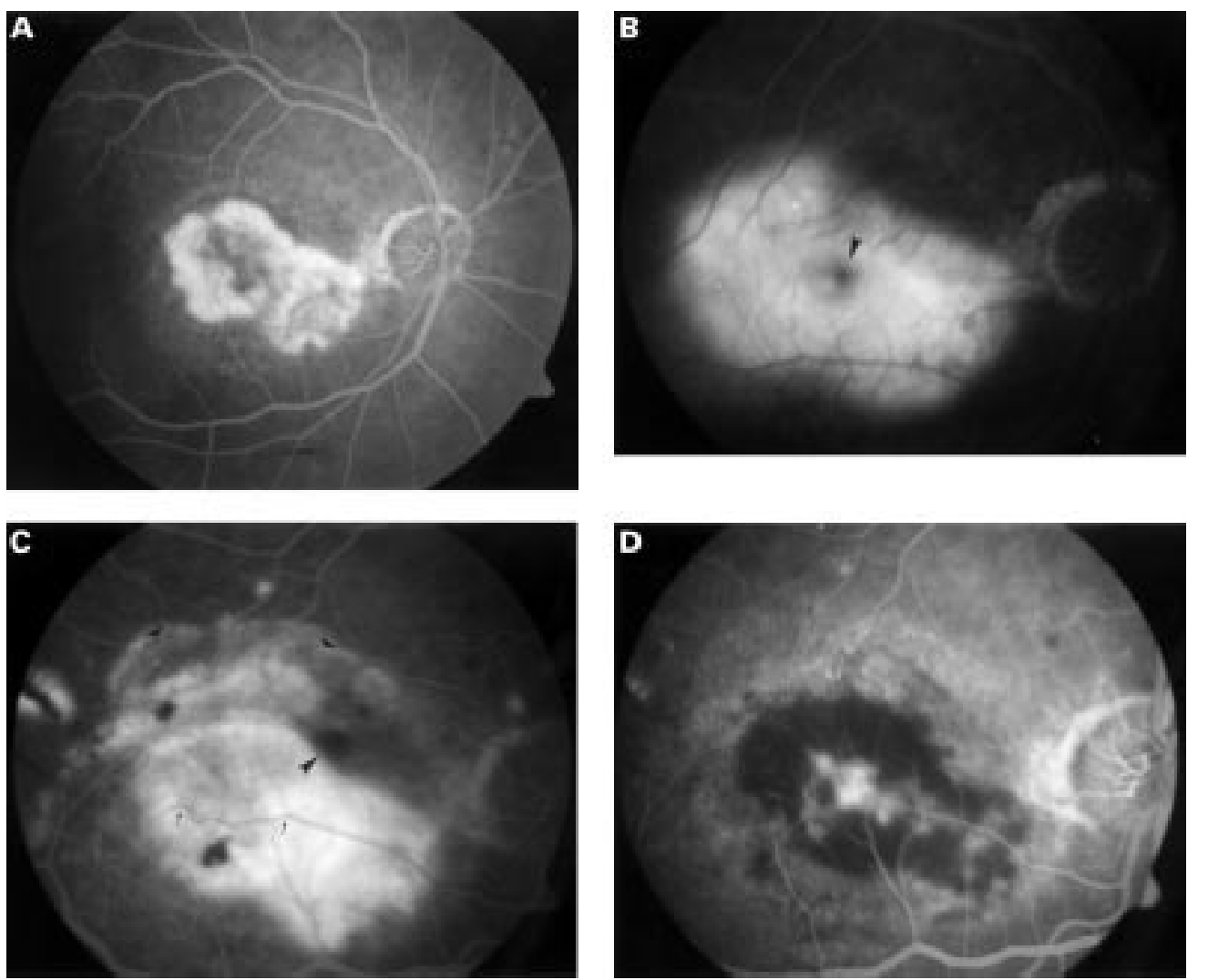

Figure 4 Preoperative fluorescein angiogram of the right eye of patient 3 with a very large classic subfoveal CNVM. Early $(A)$ and late $(B)$ frames of the angiogram are shown. Arrowhead indicates the site of the fovea. (C) Postoperatively, the fovea (large arrowhead) was relocated superonasally. Note the superonasal displacement of the retinal vessels (arrows), and the area of hyperfluorescence which corresponded to RPE changes observed on slit lamp biomicroscopy (small arrowheads). (D) Two weeks after photocoagulation, closure of the CNVM was noted.

ance of a 360 degree retinotomy in the extreme peripheral retina (which may have led to minimal dispersion of RPE cells into the vitreous cavity), and/or to other unidentified factors. The use of 360 degree retinotomy, however, produces torsional diplopia and requires extraocular muscle surgery. ${ }^{25}$ This adds to the complexity and the length of the surgical procedure.

In order to reduce the rate of complications and the need for large retinotomies, scleral shortening techniques have been devised as an alternative option in order to create redundant retinal tissue for foveal displacement. ${ }^{20-23}$ In these procedures retinal redundancy is obtained by scleral resection or imbrication. The retina is left detached at the end of the surgery and a bubble of air or gas, which partially fills the vitreous cavity, is injected. While the retina is detached the weight of the subretinal fluid and the flotation force of the bubble of air or gas tends to create inferior retinal redundancy while the patient is sitting up. Superior foveal displacements are more difficult to achieve using these surgical techniques. Although scleral shortening techniques appear to be safer than large retinotomies, complications still exist. Tilting and distortion of the image can occur, although these symptoms are usually transient and not problematic for the patient. Retinal detachment and retinal folds involving the fovea, which usually require additional surgery, have been reported..$^{20-23}$

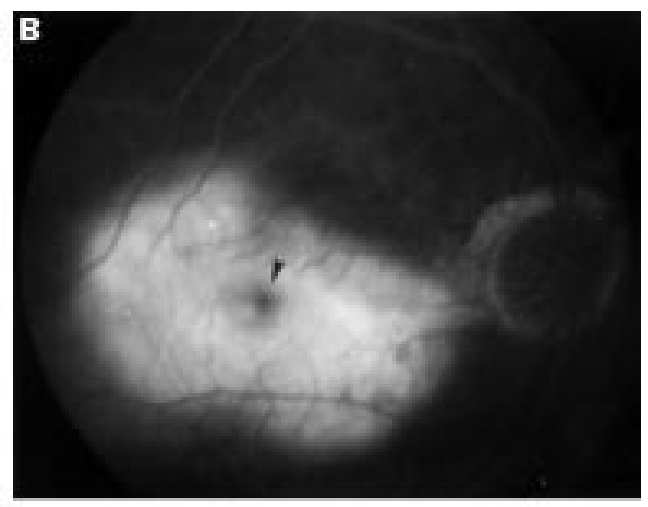



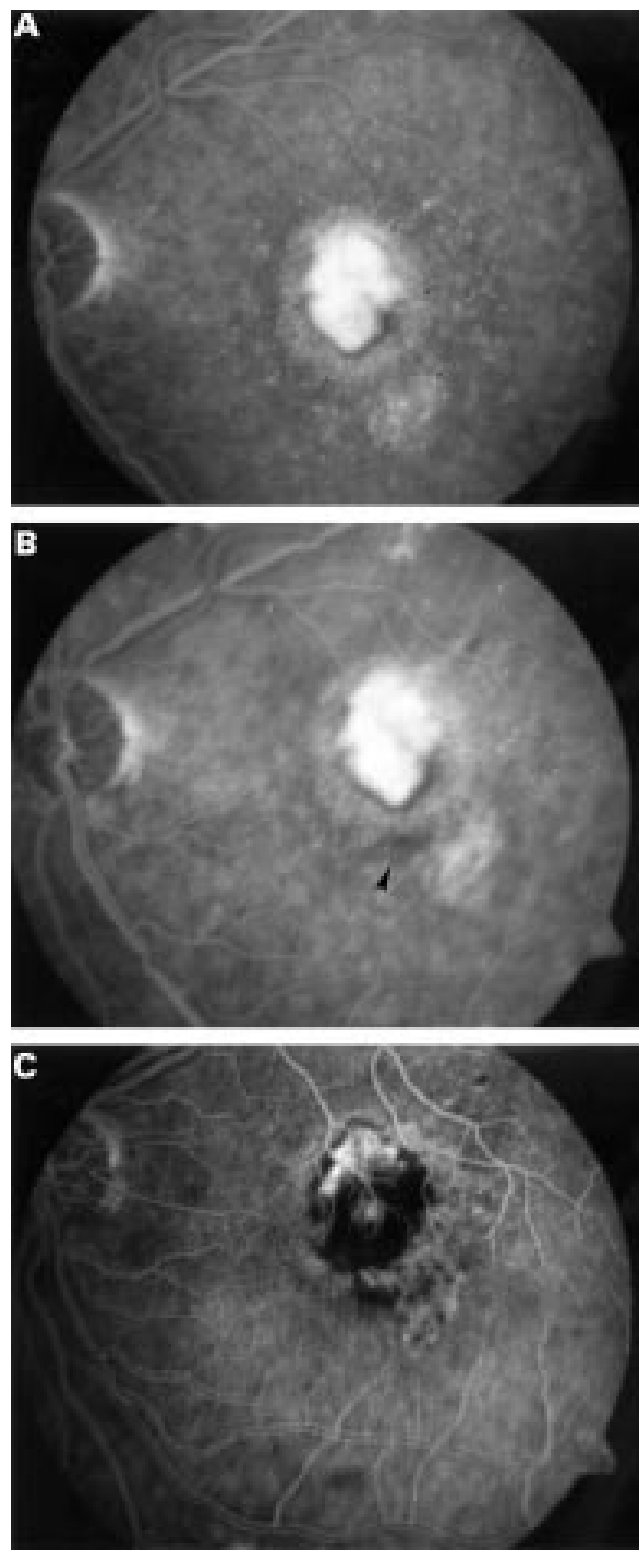

Figure 5 (A) Preoperative fluorescein angiogram of the left eye of patient 4 showing a subfoveal CNVM. A classic and an occult (arrows) component were present. (B) Postoperatively, the CNVM was extrafoveal (arrowhead indicates relocated fovea). (C) Two weeks after laser treatment, incomplete closure of the CNVM was

observed - that is, an area of persistence of CNVM in the non-foveal side was appreciated but remained stable with no further treatment during the follow up.

In the present series foveal relocation by RNR was performed in nine consecutive patients. The surgical technique is based on the principle that retinal redundancy can be obtained by redistribution of the retinal tissue, with no need for scleral shortening or relieving retinal incisions. ${ }^{26}$ The fact that retinal folds are not always observed after macular relocation surgery, whichever the technique employed, led us to conclude that a degree of stretching and/or compression of the retinal tissue was taking place. We have referred to this phenomenon as tissue redistribution, ${ }^{26}$ and we have used it as the basis for the current surgical approach. Our observation has been supported recently by de Juan and Vander ${ }^{27}$ who were able to achieve foveal displacement in one patient in whom macular relocation surgery did not involve relieving retinal incisions or scleral shortening.

A single retinotomy was used to detach the retina in all but one case in which rupture of a foveal cyst allowed passage of subretinal saline into the vitreous cavity preventing the detachment of the retina beyond that limit. In this patient, an additional retinotomy was required to produce a complete retinal detachment. In all cases the infusion retinotomy was sited anterior to the superotemporal vascular arcade. Initially, the force used to detach the retina was the hydrostatic pressure from the saline infusion. The saline infusion into the subretinal space was purposely stopped before the retinal detachment involved the macula, since attempts to detach the macula by hydrostatic pressure may lead to full thickness macular hole formation. Completion of the retinal detachment was achieved by a gentle rocking motion of the eye and a "tidal" progression of the detachment into the macula (Fig 1 (bottom)) using the inertia exerted by the subretinal fluid in the air filled eye.

Displacement of the fovea was achieved by using a retinal brush and by "sweeping" the slightly detached retinal tissue. Mild damage to the RPE was observed in two eyes on fundus examination and fluorescein angiography, possibly as a result of this retinal "sweeping". It should be noted that, although displacement of the neurosensory retinal was invariably observed following the retinal "sweeping", a tendency for the retina to return to its original anatomical position was also seen, even after PFCL was injected. To overcome this "positional memory" it was necessary to gently stroke the retina for several minutes until no reverse sliding movement was appreciated. In this regard, it appeared that stabilisation of the retina in its new location was related not only to the gravitational effect of the PFCL but also to other factors such as the evacuation of fluid from the subretinal space by the RPE pump.

It has been shown that after surgical removal of CNVM in ARMD the postoperative area of bare RPE appears to be greater than the vascular net observed in fluorescein angiography. ${ }^{12} 13$ Similarly, the absolute scotoma produced by the presence of a CNVM appears to be smaller than that observed after the surgical removal of the neovascular complex. ${ }^{28} 29$ These findings may suggest that surgical removal of the CNVM may be accompanied by removal of surrounding RPE and/or photoreceptors. For this reason we elected to treat the CNVM, postoperatively, with laser rather than to remove it at the time of the surgery.

All forms of macular relocation surgery involve detachment of the neurosensory retina from the RPE. A degree of RPE cell dispersion may occur during this manoeuvre which could increase the risk of PVR. In the current series retinal detachment complicated by PVR was not encountered. Several factors may have influenced this favourable outcome. Thus, the slow and "gentle" detachment of the retina, obtained by the rocking technique described above, may have liberated fewer RPE cells from 
Bruch's membrane. The use of a single small retinotomy for infusion, the exchange of preretinal fluid with air, and the injection of PFCL may have been important factors in minimising the seeding of any dispersed RPE cells into the retinal surface. Silicone oil was used to provide temporary postoperative tamponade; the clear media obtained by using silicone oil also allowed early postoperative assessment of the CNVM by fluorescein angiography and photocoagulation treatment.

A number of complications were observed which limited, in some cases, the potential for visual improvement. In two eyes, macular retinal vessel closure occurred at the time of laser treatment. Since laser photocoagulation had to be performed through the bubble of silicone oil, it was thought that this complication could be related to an increased laser uptake by the retina related to the lack of thermal conductivity through the silicone oil. In these two eyes, failure of improvement in visual acuity also appeared to be related to the later development of cystoid macular oedema in one eye and an ERM in the other.

In conclusion, foveal relocation by RNR appears to be a technically feasible alternative to other published techniques. However, although no PVR was observed, other complications occurred. Only two of the nine patients in this series experienced an improvement in visual acuity, but further refinements in the surgical technique and better selection of cases may improve visual outcomes in the future.

We would like to thank James McGalliard, Carl Groenewald, and Simon Harding for their support. We also appreciate the support and advice given by many ophthalmologists from UK our technique for foveal relocation.

1 Macular Photocoagulation Study Group. Argon laser photocoagulation for neovascular maculopathy after five years: results from randomized clinical trials. Arch Ophthal mol 1991;109:1109-14.

2 Macular Photocoagulation Study Group. Krypton laser photocoagulation for neovascular lesions of age-related macular degeneration: results of a randomized clinical trial. Arch Ophthalmol 1990;108:816-24.

3 Macular Photocoagulation Study Group. Laser photocoaacular Photocoagulation Study Group. Laser photocomacular degeneration: results of a randomized clinical trial. Arch Ophthalmol 1991;109:1220-31.

4 Macular Photocoagulation Study Group. Laser photocoagulation of subfoveal recurrent neovascular lesions in agerelated macular degeneration: results of a randomized clinical trial. Arch Ophthalmol 1991;109:1232-41.

5 Macular Photocoagulation Study Group. Laser photocoagulation of subfoveal neovascular lesions in age-related macular degeneration: updated findings from two clinical trials. Arch Ophthalmol 1993;111:1200-9.

6 Finger PT, Chakravarthy U, Augsburger JJ. Radiotherapy and treatment of age-related macular degeneration. External beam radiation therapy is effective in the treatment of age-related macular degeneration. Arch Ophthalmol 1998; 116:1507-11.

7 D'Hollander F, Stalmans P, Van Limbergen E, et al. Retrospective study on the evolution of visual acuity after external beam radiotherapy (20 Gy, 2 Gy fractions) for nabfoveal choroidal neovascular membranes in ARMD. Bull Soc Belge Ophtalmol 1998;270:27-34.
8 Bergink GJ, Hoyng CB, van der Maazen RW, et al. A randomized controlled clinical trial on the efficacy of radiation therapy in the control of subfoveal choroidal neovascularization in age-related macular degeneration: radiation versus observation. Graefes Arch Clin Exp Ophthalmol 1998; 236:321-5.

9 Miller JW, Schmidt-Erfurth U, Sickenberg M, et al. Photodynamic therapy with verteporfin for choroidal neovascuarization caused by age-related macular degeneration. Results of a single treatment in a phase 1 and 2 study. Arch Ophthalmol 1999;117:1161-73.

10 Schmidt-Erfurth U, Miller JW, Sickenberg M, et al. Photodynamic therapy with verteporfin for choroidal neovascularization caused by age-related macular degeneravascularization caused by age-related macular degeneraOphthalmol 1999;117:1177-87.

11 Treatment of Age-Related Macular Degeneration with Photodynamic Therapy (TAP) Study Group. Photodynamic therapy of subfoveal choroidal neovascularization in age-related macular degeneration with verteporfin. Oneyear results of 2 randomized clinical trials-TAP report 1. Arch Ophthalmol 1999;117:1329-45.

12 Ormerod LD, Puklin JE, Frank RN. Long-term outcomes after the surgical removal of advanced subfoveal neovascuar membranes in age-related macular degeneration. Ophthalmology 1994;101:1201-10.

13 Berger AS, Kaplan HJ. Clinical experience with surgical removal of subfoveal neovascular membranes. Ophthalmolgy 1992;99:969-76.

14 Lambert HM, Capone A Jr, Aaberg TM, et al. Surgical excision of subfoveal neovascular membranes in age-related macular degeneration. Am f Ophthalmol 1992;113:257-62.

15 Thomas MA, Grand MG, Williams DF et al. Surgical management of subfoveal choroidal neovascularization. Ophthalmology 1992;99:952-68.

16 Machemer R, Steinhorst UH. Retinal separation, retinotomy, amd macular relocation, I: experimental studies in the rabbit eye. Graefes Arch Clin Exp Ophthalmol 1993;231: 629-34.

17 Machemer R, Steinhorst UH. Retinal separation, retinotomy, amd macular relocation, II: a surgical approach for otomy, amd macular relocation, II: a surgical approach for Ophthalmol 1993;231:635-41.

18 Ninomiya Y, Lewis JM, Hasegawa T, et al. Retinotomy and foveal translocation for surgical management of subfoveal choroidal neovascular membranes. Am f Ophthalmol 1996; 122:613-21.

19 Imai K, Loewenstein A, de Juan E Jr. Translocation of the retina for management of subfoveal choroidal neovascularization, I: experimental studies in the rabbit eye. $\mathrm{Am} \mathcal{F O} \mathrm{Oph}$ thalmol 1998;125:627-34.

20 De Juan E Jr, Loewenstein A, Bressler NM, et al. Translocation of the retina for management of subfoveal choroidal neovascularization. II: A preliminary report in humans. $\mathrm{Am}$ f Ophthalmol 1998;125:635-46.

21 Fujikado T, Masahito O, Saito Y, et al. Visual function after foveal translocation with scleral shortening in patients with myopic neovascular maculopathy. Am f Ophthalmol 1998; 25:647-56.

22 Fujikado $\mathrm{T}$, Ohji $\mathrm{M}$, Hayashi $\mathrm{A}$, et al. Anatomic and functional recovery of the fovea after foveal translocation surgery without large retinotomy and simultaneous excision of a neovascular membrane. Am $\mathcal{F}$ Ophthalmol 1998;126:839-42.

23 Lewis H, Kaiser PK, Lewis S, et al. Macular translocation for subfoveal choroidal neovascularization in age-related macular degeneration: a prospective study. Am $\mathcal{F}$ Ophthalmol 1999;128:135-46.

24 Wolf S, Lappas A, Weinberger AWA, et al. Macular translocation for surgical management of subfoveal choroidal neovascularizations in patients with AMD: first results. Graefes Arch Clin Exp Ophthalmol 1999;237:51-7.

25 Eckardt C, Eckardt U, Conrad H. Macular rotation with and without counter-rotation of the globe in patients with age-related macular degeneration. Graefes Arch Clin Exp Ophthalmol 1999;237:313-25.

26 Wong D, Lois N, Groenewald C, et al. Foveal relocation by tissue redistribution. Klin Monatsbl Augenheilkd 1999;215: 20.

27 De Juan E, Vander JF. Effective macular translocation without scleral imbrication. Am f Ophthalmol 1999;128:380-2. 28 Hudson HL, Frambach DA, Lopez PF. Relation of the functional and structural fundus changes after submacular surgery for neovascular age-related macular degeneration. surgery for neovascular age-related
Br f Ophthalmol 1995;79:417-23.

29 Tsujikawa M, Sawa M, Lewis JM, et al. Chorioretinal damage caused by the excision of choroidal neovascularization. Am $\mathcal{F}$ Ophthalmol 1998;126:348-57. 